\title{
DC Capacitor Voltage Control Strategy for the Cascaded STATCOM
}

\author{
Zhang Min ${ }^{1,3, *}$, Zhang Yiwei $^{2}$ and Chen Libing ${ }^{3}$
}

${ }^{1}$ State Grid Henan Skills Training Center, Zhengzhou, 450001, China

${ }^{2}$ College of Sciences, Henan Agricultural University, Zhengzhou, 450002, China

${ }^{3}$ School of Information and Electrical Engineering, China University of Mining and Technology, Xuzhou, 221116, China

\begin{abstract}
In order to solve the DC capacitor voltage balance problem of the cascaded static synchronous compensator (STATCOM), a software method is presented. On the basis of overall control, a zero sequence injection method is used to realize the clustered balancing control. By using this method, a star-connected cascaded STATCOM will have a certain ability to compensate the unbalance load. An improved carrier disposition pulse width modulation method is proposed to realize the individual balancing control problem. By using the proposed PWM method, the charging and discharging time of the capacitors can be controlled by changing the distributive rule of modulation signal according to the capacitor voltages. The results of simulation and practical application show the validity of the proposed control strategy.
\end{abstract}

Keywords: Static synchronous compensator, cascaded, DC capacitor voltage balance control, carrier disposition PWM.

\section{INTRODUCTION}

STATCOM (static synchronous compensator) is the most advanced reactive power compensation device currently, with excellent compensation performance [1-3]. Compared with other STATCOM, the cascaded STATCOM is relatively structured simply, easy to expand and modularize, able to realize split phase control and redundant running, etc. [4, 5], which is particularly suitable for operation in mediumvoltage and high-voltage distribution network.

STATCOM's DC capacitor voltage plays a supporting role and the cascaded STATCOM is influenced by component values, the inverter bridge loss, pulse delay because STATCOM' each power unit is in DC capacitor independence, which causes DC capacitor voltage imbalance [6,7], and adverse effects on an harmonic characteristic of output, when it is severe, some links will be over-voltage causing unsafe operation of devices. Thus, it is necessary to look for a quick and effective method for equalizing voltages. The existing equalizing voltages method can be divided into hardware way and software way.

In hardware way, there are typical methods based on the AC bus voltage energy exchange and the DC bus energy exchanges $[8,9]$. The hardware way is complicated and expensive; therefore, this paper presents research on software equalizing strategy. The software equalizing method are various [10-14], but most of them are complex and difficult to achieve, or in the potential stability problems. This paper aims to propose an industry equalization method which is easy to achieve, and it briefly introduces the common cascaded STATCOM control strategy, then the DC capacitor control-related issues are discussed, focusing on the DC equalizing control strategy, solving the inter-phase voltage equalizing problem based on zero-sequence voltage injection method. For the problem of external phases equalizing, it proposes an improved carrier disposition PWM method. At last, the simulation and industry verification is shown.

\section{CASCADED STATCOM CURRENT CONTROL}

Due to the grid voltage disturbances and current coupling of cascaded STATCOM, utility voltage feed forward control and output current decoupling control are usually used, control block diagram is shown in Fig. (1). In the Figure, fundamental active current command signal icd* is gotten from the DC voltage control loop, and means reactive current reference value icq* is obtained through the reactive detection of the load current.

By calculating abc-dq transform for output currents ica, icb, icc of STATCOM device, we obtained icd, icq in synchronous rotating coordinate system, which are corresponding to the actual device's active and reactive current respectively, then compare them separately with icd* and icq*, the STATCOM's output voltage command signal vcd*, vcq* are obtained by feed forward decoupling the error by PI controller. The three-phase output voltage modulation wave vca*, $\mathrm{vcb}^{*}$ 及 $\mathrm{vcc}^{*}$ are obtained by abc-dq transform of $\mathrm{vcd}^{*}$, vcq*, and finally through modulation the output PWM waveform is gotten to obtain the desired current compensation.

When STATCOM do reactive compensation alone, the command signals icd* and icq* are DC value, which control can be tracked without static error by PI control, but STAT$\mathrm{COM}$ requires both harmonic and unbalance compensation component, the command signal will contain alternating 


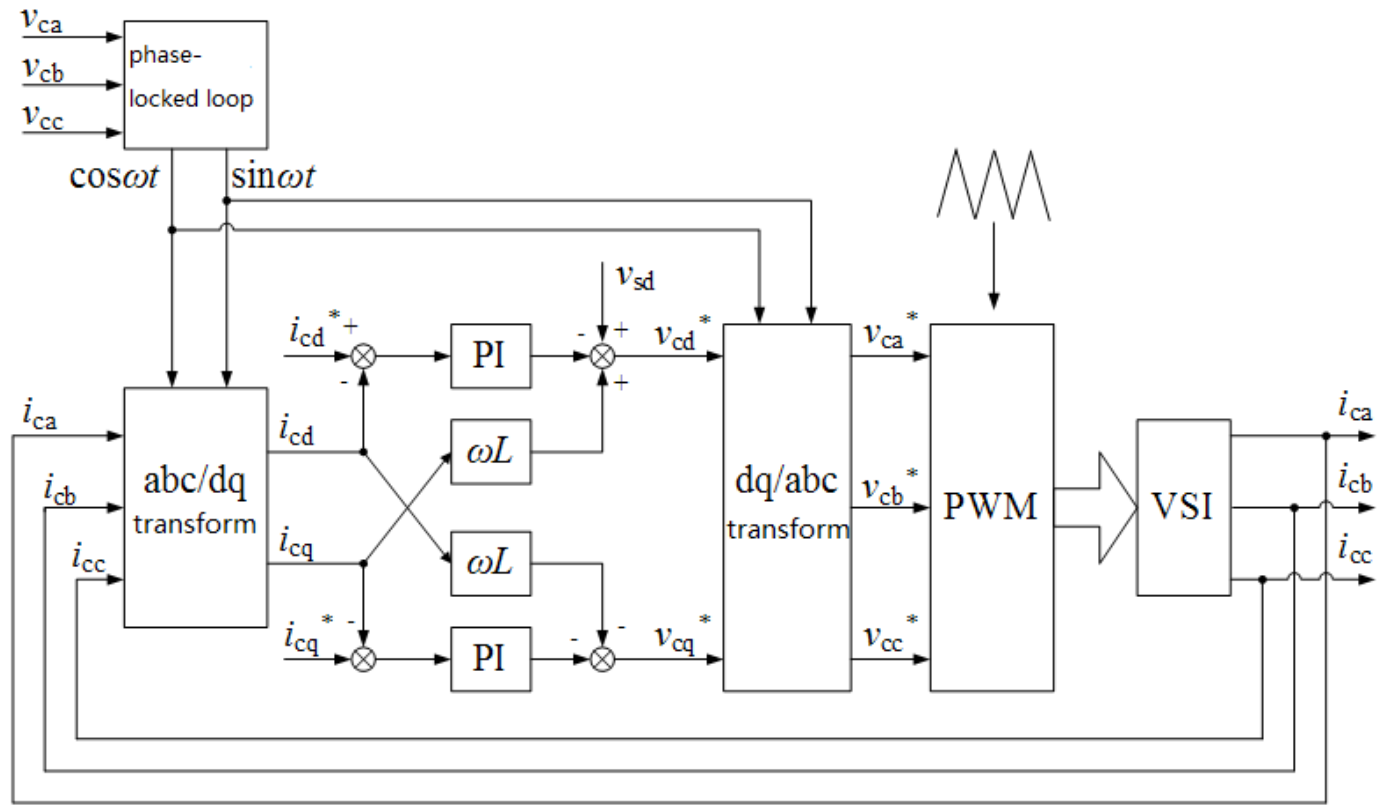

Fig. (1). Control diagram of cascaded STATCOM.

component, and the ordinary PI control will not achieved good tracking compensation effect, thus, repeating control and resonance control technology can be used.

\section{INTRODUCTION OF DC CAPACITOR CONTROL}

DC capacitor is a key part of cascaded STATCOM, its controls mainly consists of two aspects, one is how to establish initial voltage of the capacitor, and the other is how to control the capacitor voltage of the normal operation.

The Establishment of initial DC capacitor voltage is usually done in the device's startup process, because STATCOM AC side filter inductor is usually small, there will be a significant impact current without control on the device at starting time, which may cause the capacitor voltage substantial overshoot, a serious threat to the safe operation of the device. Thus, STATCOM must take soft start measures. In this paper, the STATCOM soft start can be divided into resistance and control soft starting two stages. After the device is powered up, the inverter IGBT is blocked, DC capacitor is charged by uncontrolled rectifier circuit consisting of soft start resistor and inverter bridge IGBT. The value soft start resistor is determined in accordance with current value we want to control, generally peak current of soft resistor is less than IGBT current levels, and it is also necessary to consider the soft start resistor's thermal capacity. After stabilizing charge voltage of DC side capacitor by the soft start resistor, it has to do further charge to make the capacitor voltage reach the desired voltage to work properly. Meantime, bypass the soft start resistor, open IGBT driving, set the reactive current command as zero, and control Inverter Bridge to work on PWM rectifier state status in odder to continue charging the capacitor. In order to limit the charging current of this step, the voltage control loop command voltage can be set to rise by a certain slope gradually. The capacitor's reference voltage value Vref_step is calculated by the following formula (1) in each control cycle

$$
V_{\text {ref_step }}=\frac{V_{\text {ref }}-V_{0}}{T \cdot f_{c}}
$$

In formula (1), Vref is the reference value of DC voltage, $\mathrm{V} 0$ is the initial DC voltage value of soft start, and $\mathrm{T}$ is the time of control soft start, fc is control frequency of STATCOM. By adjusting the Vref_step, we can easily change the time of controlling soft start. If capacitor voltage rises to Vref, the controlling soft start stops, and the device goes into the normal operating state. The effect of the soft start strategy of STATCOM is shown in Fig. (1) (a two-stage cascade of STATCOM by matlab simulation), the entire voltage rising process is steady, and the device output current is always small.

After the device going into normal operation, the capacitor voltage control device is another key point, and there are three control method mentioned in the existing literature $[15$, $16]$

(1) The capacitor voltage is kept constant, which means that regardless of STATCOM in capacitive or inductive status, DC side voltage remains unchanged. The disadvantage of this approach is that when STATCOM operates in inductive status, the inverter output voltage will be less than the system voltage, and the inverter voltage modulation ratio $M$ will be a smaller value, leading to deterioration of the output characteristics of the device.

(2) Keep the modulation ratio $\mathrm{M}$ as constant (usually taking the maximum modulation ratio). The advantage of 
this approach is that $\mathrm{M}$ was maintained at maximum, and the output voltage harmonic distortion is small. The disadvantage is that the capacitor voltage changes on reactive change and capacitor's characteristics determine that the transient response is slow.

(3) Capacitor reference voltages are one high and one low two values, if the devices works in capacitive status, choose high reference voltage, and choose low reference voltage in inductive status. This avoids the case of a small voltage modulation ratio $\mathrm{M}$ occurs, but it also increases the complexity of control.

When STATCOM is used for distribution network, besides reactive power compensation, it is often required to take into account certain harmonic compensation and asymmetry component compensation. At this time, the device must have the ability of fast dynamic response. In the above three control methods, (1) is most simple and can provide the fastest dynamic response meet the requirements, and because of cascaded STATCOM structure has the advantage of small output voltage harmonic distortion, it able to make up for the method (1)'s the shortcomings to a certain extent, so method (1) is used in this paper to control the DC side capacitor voltage constant. By this method, the DC capacitor voltage problem of normal operation is equalization problem.

\section{DC CAPACITOR VOLTAGE CONTROL STRATE- GIES}

\subsection{Capacitor Voltage Overall Control}

First we have to consider the overall capacitor voltage control scheme. Supposing that each power unit's DC capacitor is $\mathrm{C}$, the capacitor voltage is always $\mathrm{Vdc}$, and set the grid voltage as follows

$$
\left[\begin{array}{c}
v_{\mathrm{sa}} \\
v_{\mathrm{sb}} \\
v_{\mathrm{sc}}
\end{array}\right]=\sqrt{2} \times V_{\mathrm{s}} \times\left[\begin{array}{c}
\sin \omega t \\
\sin (\omega t-2 \pi / 3) \\
\sin (\omega t+2 \pi / 3)
\end{array}\right]
$$

STATCOM output phase voltage is:

$$
\left[\begin{array}{c}
v_{\mathrm{ca}} \\
v_{\mathrm{cb}} \\
v_{\mathrm{cc}}
\end{array}\right]=K \times V_{\mathrm{dc}} \times\left[\begin{array}{c}
\sin (\omega t-\delta) \\
\sin (\omega t-\delta-2 \pi / 3) \\
\sin (\omega t-\delta+2 \pi / 3)
\end{array}\right]
$$

$\mathrm{K}=\mathrm{N} \times \mathrm{m}, \quad(\mathrm{N}$ is cascade number, $\mathrm{m}$ is modulation ratio), $\delta$ 为 is the phase difference between output voltage and the grid voltage. Dq transforming formula (3):

$$
\left[\begin{array}{c}
v_{\mathrm{cd}} \\
v_{\mathrm{cq}}
\end{array}\right]=\sqrt{\frac{3}{2}} K \times V_{\mathrm{dc}} \times\left[\begin{array}{c}
\cos \delta \\
\sin \delta
\end{array}\right]
$$

Unbalanced capacitor voltage of each power unit is not considered, so that the capacitor voltage of each power unit is the average of the capacitor voltage vdc(t), according to energy conservation, we can get

$$
\frac{d}{d t}\left[3 N \times \frac{1}{2} C v_{\mathrm{dc}}(t)^{2}\right]=v_{\mathrm{cd}}(t) \times i_{\mathrm{cd}}(t)+v_{\mathrm{cq}}(t) \times i_{\mathrm{cq}}(t)
$$

Change $V_{\mathrm{dc}}$ from formula (4) for $v_{\mathrm{dc}}(t)$, and take it into formula (5)

$\frac{d v_{\mathrm{dc}}(t)}{d t}=\frac{1}{\sqrt{6}} \times \frac{K}{N C}\left[\cos \delta \times i_{\mathrm{cd}}(t)+\sin \delta \times i_{\mathrm{cq}}(t)\right]$

Because $\delta$ is often small, and $\sin \delta$ is almost 0 , we can get formula (7)

$$
\frac{d v_{\mathrm{dc}}(t)}{d t}=\frac{1}{\sqrt{6}} \times \frac{K}{N C} \times \cos \delta \times i_{\mathrm{cd}}(t)
$$

STATCOM active current control is be able to stabilize the overall DC voltage of devices. we can control the overall balance through the PI controller for capacitor voltage, output of PI controller is current loop's active current icd and command signal icd*. Operational control instructions below:

$$
i_{\mathrm{cd}}^{*}=K_{\mathrm{pV}}\left(v_{\mathrm{dc}}^{*}-v_{\mathrm{dc}}\right)+K_{\mathrm{iV}} \int\left(v_{\mathrm{dc}}^{*}-v_{\mathrm{dc}}\right) d t
$$

$$
K_{\mathrm{pV}} 、 K_{\mathrm{iV}} \text { is PI adjustable parameter. }
$$

In fact, for cascaded STATCOM, the DC voltage control loop can just control the DC side capacitor voltage, if we want to achieve a DC capacitor voltage stable and balanced of all three-phase power units, the need to join the interphase balance and internal balance are necessary.

\subsection{Inter-phase Balance Strategy Based on the Zero- Sequence Voltage Injection}

Inter-phase balance refers to that STATCOM voltage and capacitor' sum value or mean value of each phase' the power unit is equal. In literature [11], the three-phase cascaded Hbridge inverter chain is equivalent to a three-phase singlestage H-bridge unit, and the voltage balance of phases is achieved by adjusting the amplitude of each phase's modulation wave (modulation ratio), to indirectly balance each active power of phase inverter chain, so as to achieve the purpose of equalizing phase. However, this approach is likely to cause the three-phase output current imbalance, which make the device be an three-phase unbalanced load for the grid, causing serious pollution to the power grid.

Some literature propose the use of negative-sequence or zero-sequence voltage injection to achieve phase equalization $[12,13]$. Injection of negative or zero sequence voltage does not affect the overall system active power, but it can be changed each phase's absorbed active power. The literature [12] pointed out that negative sequence voltage injection is more effective than the zero-sequence voltage to produce the same active power. However, the use of zero-sequence voltage injection method is not as polluting as negative sequence 

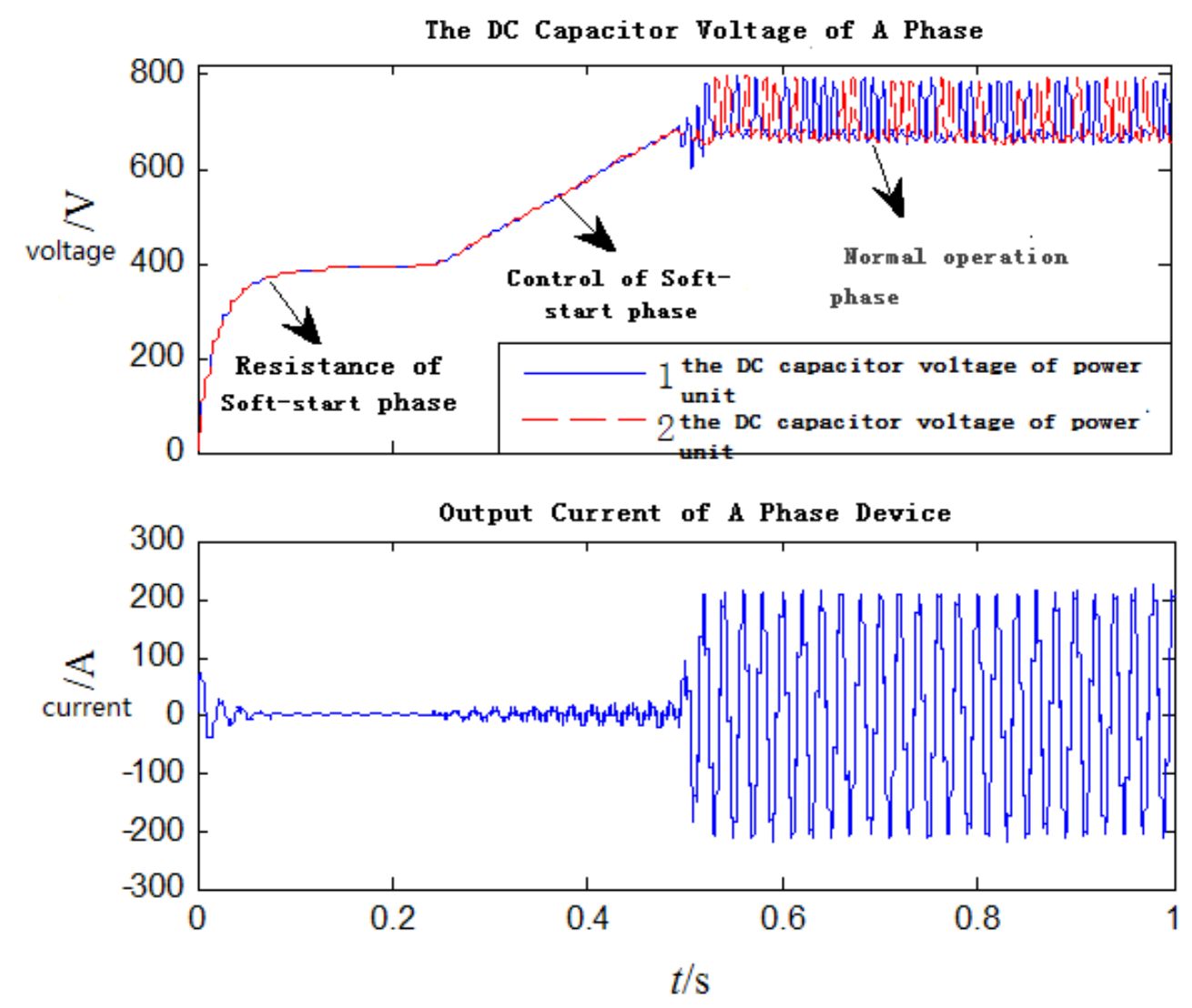

Fig. (2). Soft-start control process of STATCOM.

current negative sequence injection method, and it can remain three-phase active balance for star connected STATCOM's output negative sequence current compensation unbalance component, which avoids quite difference of phase DC voltage, thus making the star connected STATCOM obtain ability to compensate. Therefore, this paper uses the zero-sequence voltage injection method. For three-phase star-connected STATCOM, the vector relationship of its AC side output three-phase voltage, three-phase inductor current and zero-sequence voltage is shown in Fig. (3).

After injection of zero-sequence voltage vector, the three-phase output voltage becomes

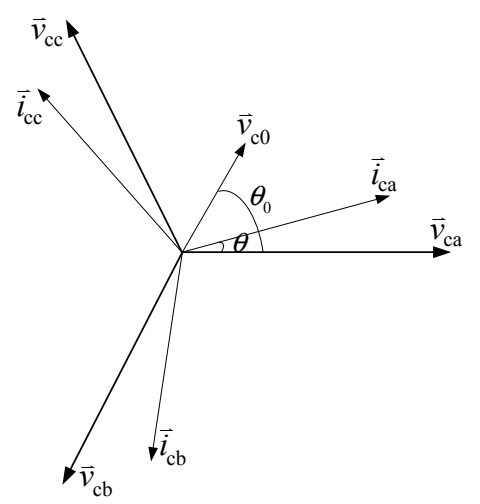

Fig. (3). Phase diagrams of AC-side voltage of STATCOM.

$$
\left\{\begin{array}{l}
\vec{v}_{\mathrm{ca}}^{*}=\vec{v}_{\mathrm{ca}}+\vec{v}_{\mathrm{c} 0} \\
\vec{v}_{\mathrm{cb}}^{*}=\vec{v}_{\mathrm{cb}}+\vec{v}_{\mathrm{c} 0} \\
\vec{v}_{\mathrm{cc}}^{*}=\vec{v}_{\mathrm{cc}}+\vec{v}_{\mathrm{c} 0}
\end{array}\right.
$$

Three-phase absorbed active power becomes:

$$
\left\{\begin{array}{l}
P_{\mathrm{a}}^{*}=P / 3+P_{\mathrm{a} 0}=P / 3+V_{\mathrm{c} 0} I_{\mathrm{c}} \cos \left(\theta-\theta_{0}\right) \\
P_{\mathrm{b}}^{*}=P / 3+P_{\mathrm{b} 0}=P / 3+V_{\mathrm{c} 0} I_{\mathrm{c}} \cos \left(\theta-\theta_{0}-\frac{2 \pi}{3}\right) \\
P_{\mathrm{c}}^{*}=P / 3+P_{\mathrm{c} 0}=P / 3+V_{\mathrm{c} 0} I_{\mathrm{c}} \cos \left(\theta-\theta_{0}+\frac{2 \pi}{3}\right)
\end{array}\right.
$$

Calculating angle and amplitude of zero-sequence voltage vector from formula (10):

$$
\begin{aligned}
& \theta_{0}=\theta-\arctan \left(\frac{2 A+1}{\sqrt{3}}\right) \\
& V_{\mathrm{c} 0}=\frac{P_{\mathrm{a}}^{*}-P / 3}{I_{\mathrm{c}} \cos \left(\arctan \left(\frac{2 A+1}{\sqrt{3}}\right)\right)}
\end{aligned}
$$

And there is 


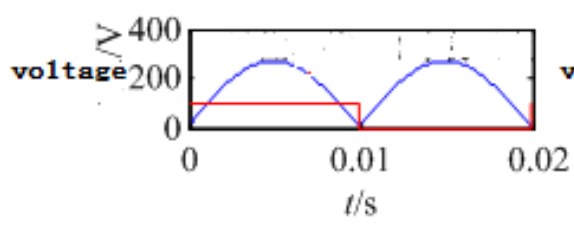

(a) The Total Modulation ithaveform

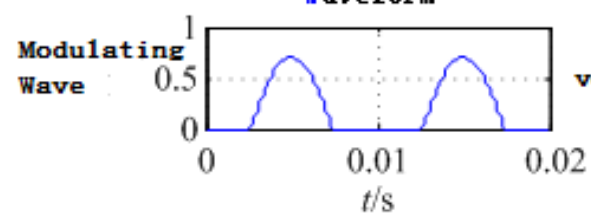

(c) Modulation "iliaveform of Ho. 1 Power Unit

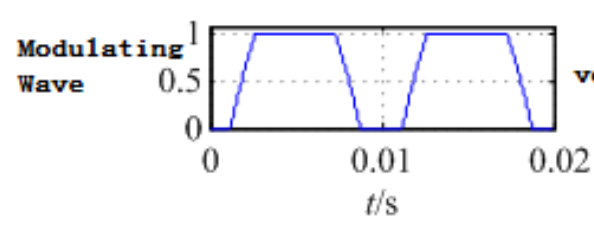

(e) Modulation "illaveform of Ho. 2 Power Unit

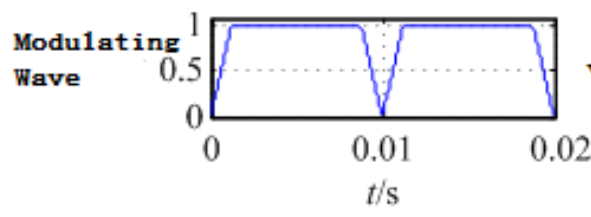

(g) Modulation itiveform of Ho. 3 Power Unit

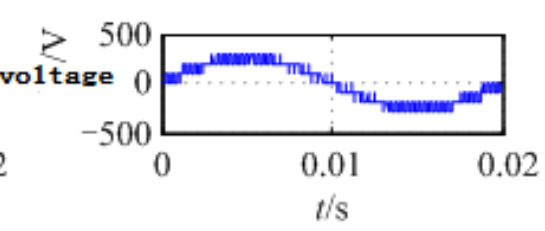

(b) Total Output Yoltage "waveform

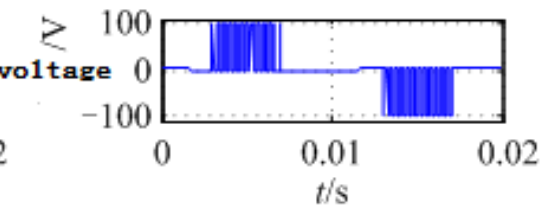

(d) PHII "ithaveform of Ho. 1 Power Unit

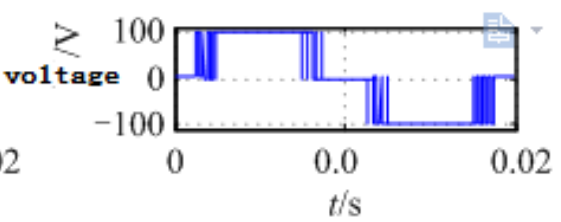

(f) PHW "Troveform of Ho. 2 Power Unit

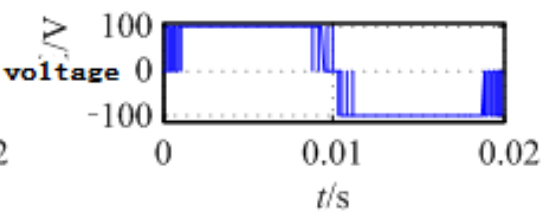

(h) PHW "waveform of Ho. 3 Power Unit

Fig. (4). Improved carrier disposition PWM.

$$
A=\frac{P_{\mathrm{b}}^{*}-P / 3}{P_{\mathrm{a}}^{*}-P / 3}
$$

\subsection{The Internal Phase Equalizing Strategy Based on Improved Carrier phase PWM Modulation}

STATCOM phase voltage sharing control objective is to make the device internal capacitor voltage of each phase of all power units to keep balance. Literature [14] proposed an approach based on active voltage cascaded vector with internal voltage equalization strategy, the active voltage vector is a unit vector parallel to the current direction, the same as the current direction vector and devices when low voltage $\mathrm{H}$ bridge is cascaded, cascaded vector of H-bridge opposite with the current direction of the device. This principle of the method is simple, but each phase of each power unit DC capacitor voltage is required for setting up a separate controller, which is more complex, with difficult parameter tuning. To omit balance the bridge DC capacitor voltage controller, this paper proposes a method by modifying the modulation strategy to directly implement equalizing internal phase.

Three-phase modulation waveform in Fig. (1) is in the final three-phase voltage reference signal. To make the inverter output voltage reference signal to obtain the required

compensation current, we also need the help of PWM modulation technique. At present the main modulation techniques commonly takes STATCOM carrier phase shifting, cascaded carrier, comprehensively considering the factors of difficult, output characteristic, this paper choose the cascaded carrier PWM modulation.

When using the traditional same cascaded carrier direction PWM method, for an n-level inverter, it requires n-1 triangular carriers, so many number of carriers lead to hardware design complexity. Therefore, this paper presents an improved method carrier cascaded PWM, taking the absolute value of the modulation wave treatment, which take the minus part of the modulation wave above the zero axis, so the triangular carrier only need to take the upside of the axis to reduce half number of carriers. In three cascaded inverters, the improved methods are shown in Fig. (4).

In Fig. (4), the total modulated waves are waveforms of the absolute value, expressed by a plus or minus sign bit. As we can see from the figure, the cascaded carrier method is equivalent to the total decomposition of the modulation waveform into $\mathrm{N}$ modulated wave (after normalization, $\mathrm{N}$ for the number of cascades), then assign it to each power unit by a certain rule. 
Table 1. The distributive rule of modulation signal.

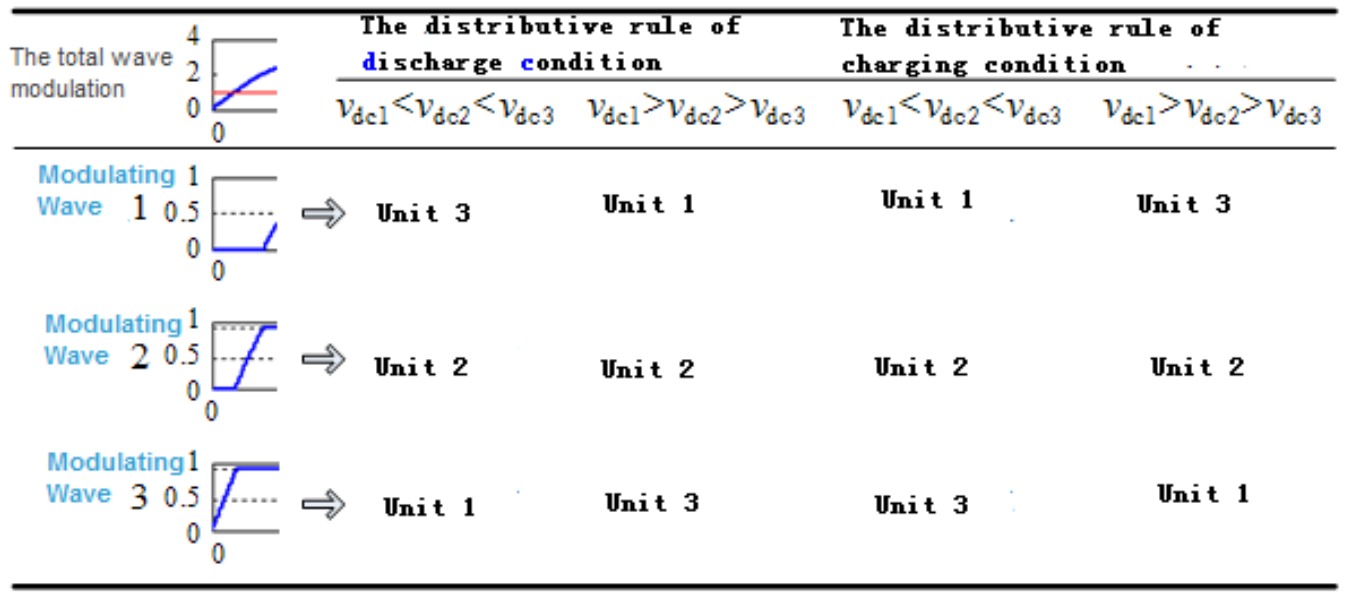

Drawbacks of the PWM carrier approach is assigned different waveform to each $\mathrm{H}$-bridge modulation, so that each $\mathrm{H}$-bridge switching frequency varies, each $\mathrm{H}$-bridge DC capacitor charging and discharging time are also different, if no measures are taken it is easy to make cascade H-bridge DC capacitor becomes more serious imbalance, thereby endangering the safe operation of the device. In order to eliminate these shortcomings and take full advantage of this modulation strategy, how to split and reasonably allocate the modulation wave is the key. In fact, if handled properly, this link is not a problem, and it can make the same with each $\mathrm{H}-$ bridge DC capacitor voltage to achieve a phase equalizing goal.

In view of the above the carrier PWM method, this paper presents a real-time adjustment of DC side capacitor voltage modulation wave distribution according to the rules, so as to realize the inverter self energy balance phase equalizing method. In a phase, for example, when the total modulation wave vca* and a phase output current ica (the grid direction is a positive direction) in the same direction, means a state of charge relative to the whole, during such a state continues, because the distribution of to the modulation waveform of each power unit is different, so each power unit DC capacitor charging time is inconsistent. When vca* and ica reversed, a phase as a whole in a discharged state, because different modulation wave, each power unit DC capacitor discharge time is also inconsistent. According to this law, we can adjust the allocation order to achieve control of the modulation wave power units for each charge and discharge time, making the DC capacitor voltage of each power unit is becoming balanced. Using this method, we need to continue to detect the direct current power unit within the same phase side capacitor voltage and means for outputting current, then the capacitor voltage to sort, determine the power distribution unit in accordance with the modulation state of charge and discharge voltage level and current capacitance wave order. Assuming a period of time, the capacitor voltage sequencing has not changed, and the capacitance charging and discharging state has not changed, during which time the allocation rule of the modulation wave remains unchanged. Allocation rules example modulated wave shown in Table $\mathbf{1}$ (still three cascaded STATCOM, for example), the table $\operatorname{vdc} 1, \operatorname{vdc} 2, \operatorname{vdc} 3$ is the voltage in the same phase 1 to the 3rd power unit DC side capacitor.

The steps of implementation are as below:

Step1: Pre-process each phase modulated signal. Take the toal signal as $v^{*} x^{*}(x=a, b, c)$ and do its absolute value calculation $\mathrm{vcx}^{*}=\operatorname{abs}\left(\mathrm{vcx}^{*}\right)$, meanwhile retain the sign bit signx, if $\mathrm{vcx}^{*}>0$, then $\operatorname{sign} \mathrm{x}=1 ; \mathrm{vcx}^{*}<=0, \quad$, then $\operatorname{sign} \mathrm{x}=0$.

Step2: Calculating each phase DC capacitor charge and discharge status flag plx. If $\operatorname{signx}=1$, and the output device current is ic $>0$ or sign $x=0$, and if ic $<0$, it is in the charge state, $\mathrm{plx}=1$; otherwise, it is in discharge status, $\mathrm{plx}=0$.

Step3: Sequencing DC capacitor voltage each phase's power unit (in an array $\operatorname{vdcx}[\mathrm{N}]$ ), prioritize the allocation of the modulation signal according to Sequencing results. If $\mathrm{plx}=1$, it means charging, we should make the lower voltage of the capacitor charging power unit occupy a long time and in the allocation of the modulation wave we should make lower capacitance voltage power unit occupy a higher priority, so after sequencing the capacitor voltages are from low to high order, and we store the array vdcx[N] the number into an array $\operatorname{idx}[\mathrm{N}]$, for example, if $\mathrm{vdcx}[\mathrm{k}]$ is minimum and $\operatorname{vdcx}[\mathrm{m}]$ is maximum, then $\operatorname{idx}[0]=\mathrm{k}$, $\operatorname{idx}[\mathrm{N}-1]=\mathrm{m}$. Conversely, if $\mathrm{plx}=0$, press the capacitor voltage in descending order, sequentially store array $\operatorname{vdcx}[\mathrm{N}]$ into array $\mathrm{idx}[\mathrm{N}]$, for example, if $\mathrm{vdcx}[\mathrm{k}]$ is minimum, $\mathrm{vdcx}[\mathrm{m}]$ is maximum, then $\operatorname{idx}[0]=\mathrm{m}, \operatorname{idx}[\mathrm{N}-1]=\mathrm{k}$.

Step4: In accordance with the priorities identified, decompose the modulation signal $\mathrm{vcx}^{*}$ into pwmox $*[\operatorname{idx}[0]] \sim$ pwmox $*[\operatorname{idx}[\mathrm{N}-1]]$, which are respectively the modulation signal of each power unit. Fig. (5) shows a flowchart of a modulation signal distribution. In Fig. (5), temp 0 and temp 1 are two temporary variables.

Step5: According to assigned modulated signal, each power do PWM output respectively. 


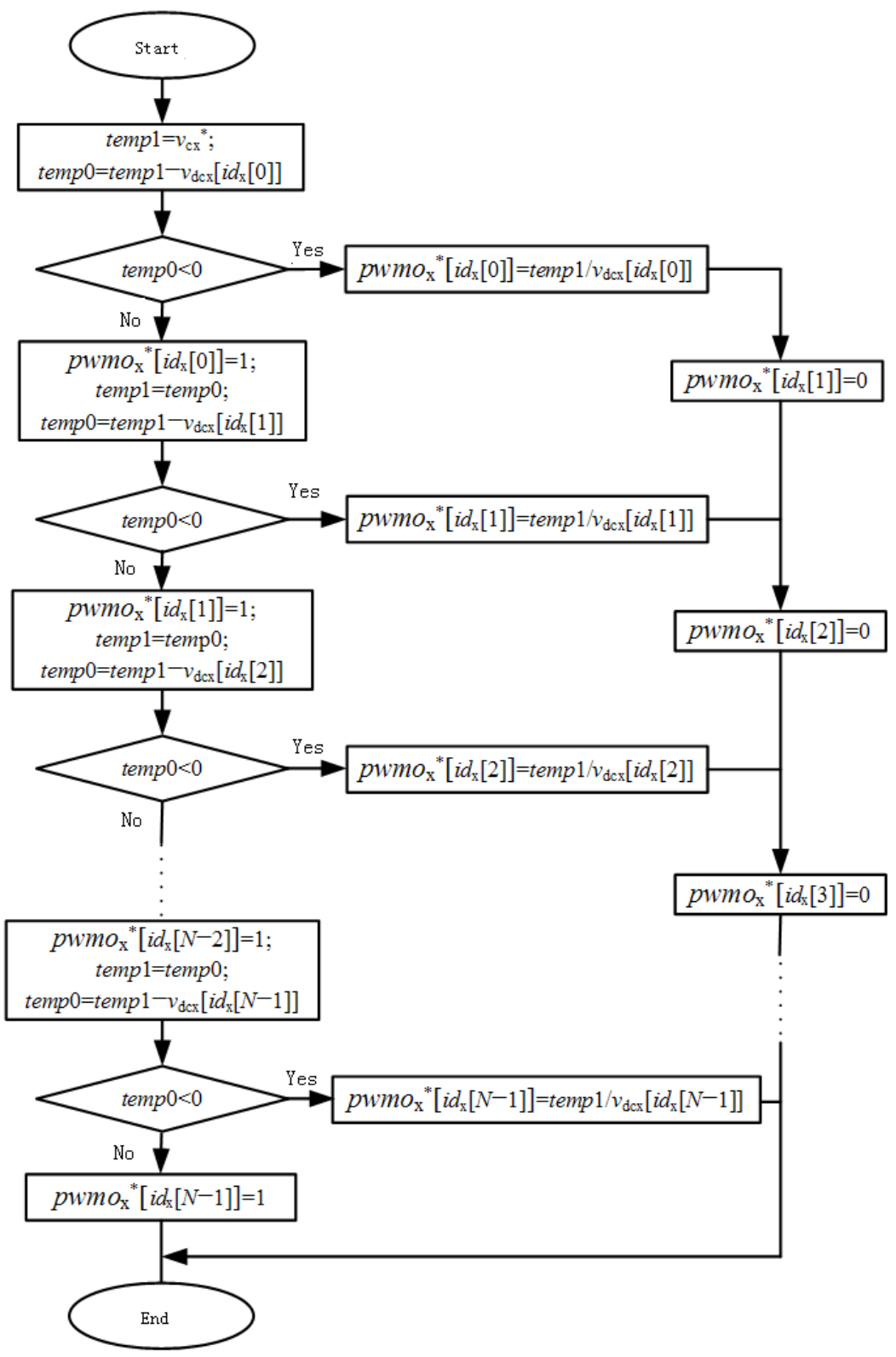

Fig. (5). Distribution of modulation signal.

By the above method, it can make the lowest voltage power unit occupy the maximum charging time during the capacitor charge, but during the capacitor discharge, the highest voltage power unit has the longest discharge time, which can make the DC voltage of each power unit become unanimous. In this process, once capacitors charging and discharging state change are detected, or capacitance voltage sequencing change is detected, the order of the modulation wave distribution will immediately change.

Finally, based on the use of this improved cascaded carrier PWM method, in order to make switching frequency equalization in the power unit H-bridge's IGBT, there are also two-arm rotation as the direction arm strategy and the chopping arm strategy to applying.

\section{SIMULATION}

In order to verify the effectiveness of the equalizing strategy proposed in this article, we use matlab to build a simulation model of STATCOM $6 \mathrm{kV}$. Each phase consists of eight cascade power units with star connection. Each power unit $\mathrm{DC}$ capacitor is $3000 \mu \mathrm{F}$, capacitor voltage reference value is $750 \mathrm{~V}$. In simulation, the load contains $100 \mathrm{~A}$ inductive reactive current. In order to verify the proposed strategy equalizing effect when the load changes dynamically, in one second, set load reactive current to do step incensement from $100 \mathrm{~A}$ to $200 \mathrm{~A}$. For comparison between the control strategy based on improved carrier cascading and the control strategy based on carrier phase shift modulated, the two methods are simulated under the same simulation environment, 


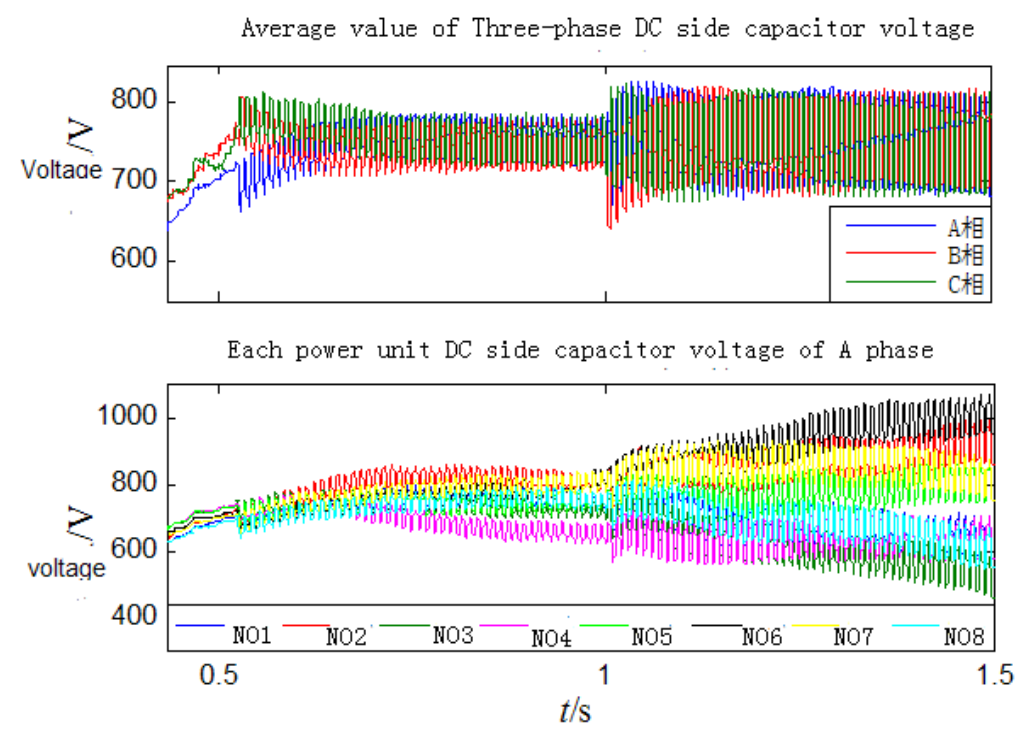

(a) Control without internal phase equalizing

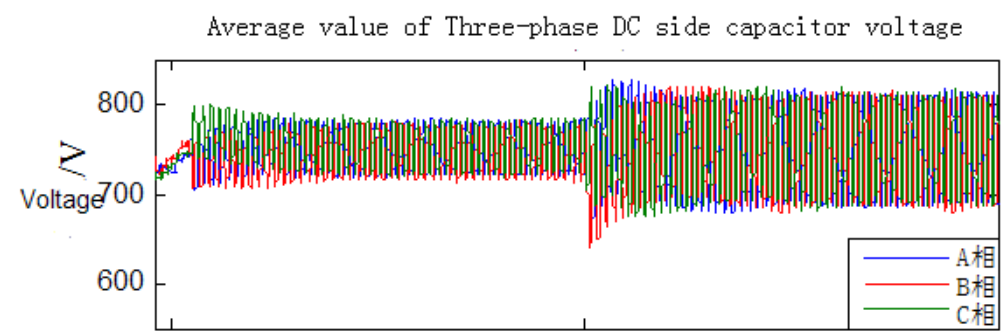

Each power unit DC side capacitor voltage of is phase

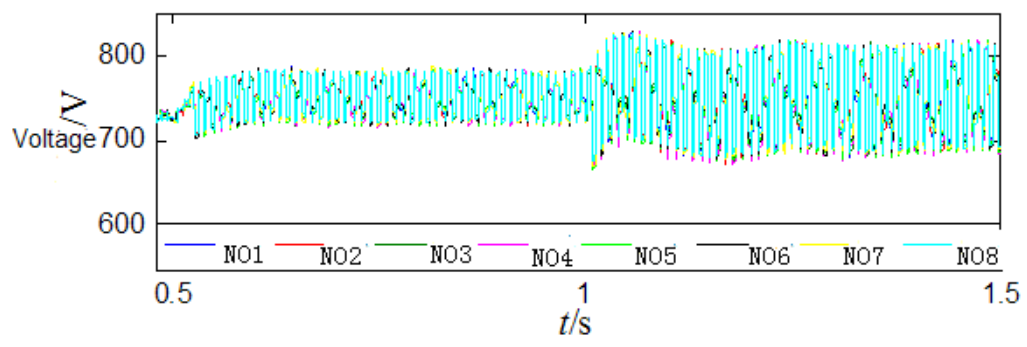

(b) Control with internal phase equalizing

Fig. (6). DC-link voltages when using CPS-SPWM.

First, the carrier phase shift modulated is tested. Select single polarity double frequency CPS-SPWM way, without adding internal phase strategy equalizing, and do test under same the three-phase parameters. The result of capacitor voltage is shown in Fig. (6a). It is seen that the average of the three-phase DC capacitor voltage are fluctuating around reference $750 \mathrm{~V}$ up and down, relatively balanced. But the Aphase capacitor voltage of each power unit appears in the imbalance, and after load becomes overload from light load, imbalances have become even more serious. This shows that although the carrier phase shift has advantages that each power unit switching frequency is relatively balanced, but pure carrier phase shift does not ensure that the capacitor voltage of each power unit in the same phase are balanced, therefore, we must add extra internal phase equalizing strategy. Based on phase shift modulation of the carrier, we do simulation again with equalizing strategy in [14], the capacitor voltage is obtained as shown in Fig. (6b) in Fig. After internal phase equalizing control, both for light load or overload, A phase of each power unit DC capacitor voltage curves are essentially coincident, and fluctuate around the reference values $750 \mathrm{~V}$ up and down, indicating that the STATCOM can achieve DC capacitor voltage equalizing control with carrier phase shift modulation.

After testing the carrier phase shift modulation method, change the modulation strategy into improved carrier cascade PWM method proposed in this paper to do test. In order 


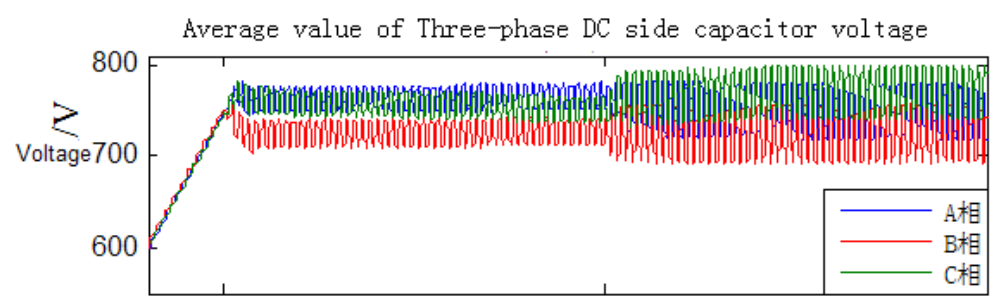

Each power unit DC side capacitor voltage of is phase

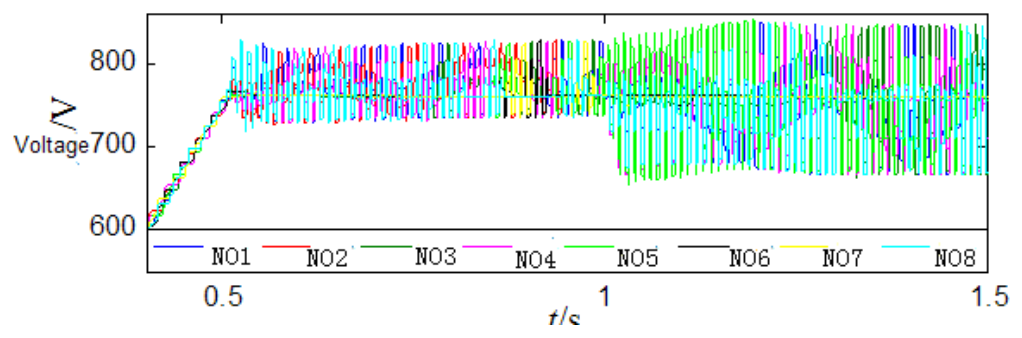

(a) control without internal phase equalizing

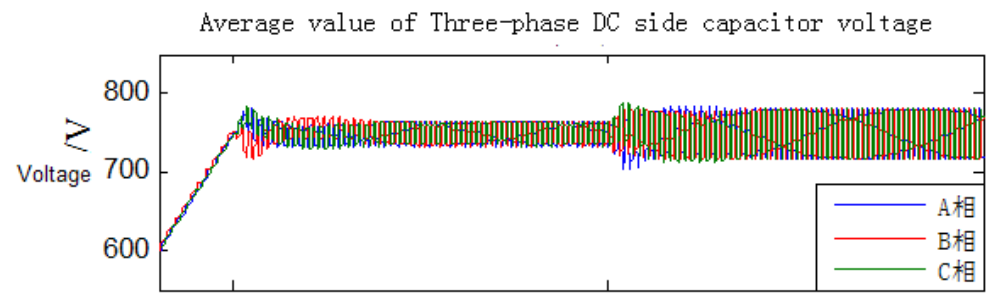

Each power unit DC side capacitor voltage of A phase

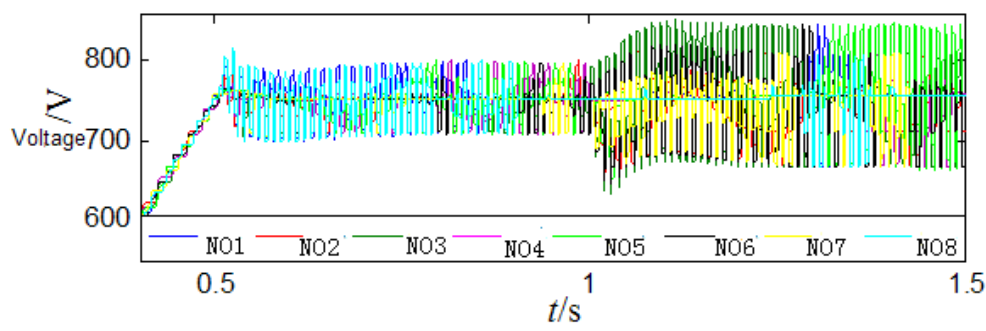

(b) Control with internal phase equalizing

Fig. (7). DC-link voltages when using improved carrier disposition PWM.

to verify that the effectiveness of the proposed approach in the three-phase parameters are not exactly the same, when testing, parallel different resistor side across the capacitor in each phase of the 1 st unit DC side, where A phase $1 \mathrm{k} \Omega, B$ phase $5 \mathrm{k} \Omega, C$ phase A phase $10 \mathrm{k} \Omega$, the other side of the DC power unit is with ideal capacitor. During the test, set the zero-sequence voltage to 0 , which means that it does not add inter phase equalizing, only using this article's improved PWM carrier cascade method. the DC capacitor voltage is in Fig. (7a), it shows that the use of this improved carrier cascade PWM will not cause the divergence in Fig. (6a), no matter light load or heavy load, each capacitor voltage in reference values are around $750 \mathrm{~V}$ normal fluctuations up and down, indicating improved PWM carrier cascade can achieve a good internal phase equalizing goal. In Fig. (7a), because it does not add phase equalization measures, although the average of the three-phase DC capacitor voltage is stable, there are differences in values and imbalance in the three phases.

On the basis of improved carrier cascade PWM method, after re-add zero phase sequence voltage injection method, the DC capacitor voltage is shown Fig (7b). It can be seen that after adding the equalizing strategy, the average of the three-phase DC capacitor voltage are in normal fluctuations around $750 \mathrm{~V}$, and three-phase DC voltage imbalance are eliminated, the zero-sequence voltage injection method has good equalizing effect.

Compare Fig. (7b) and Fig. (6b), it can also be seen that although the use of the carrier cascade and the carrier phase 


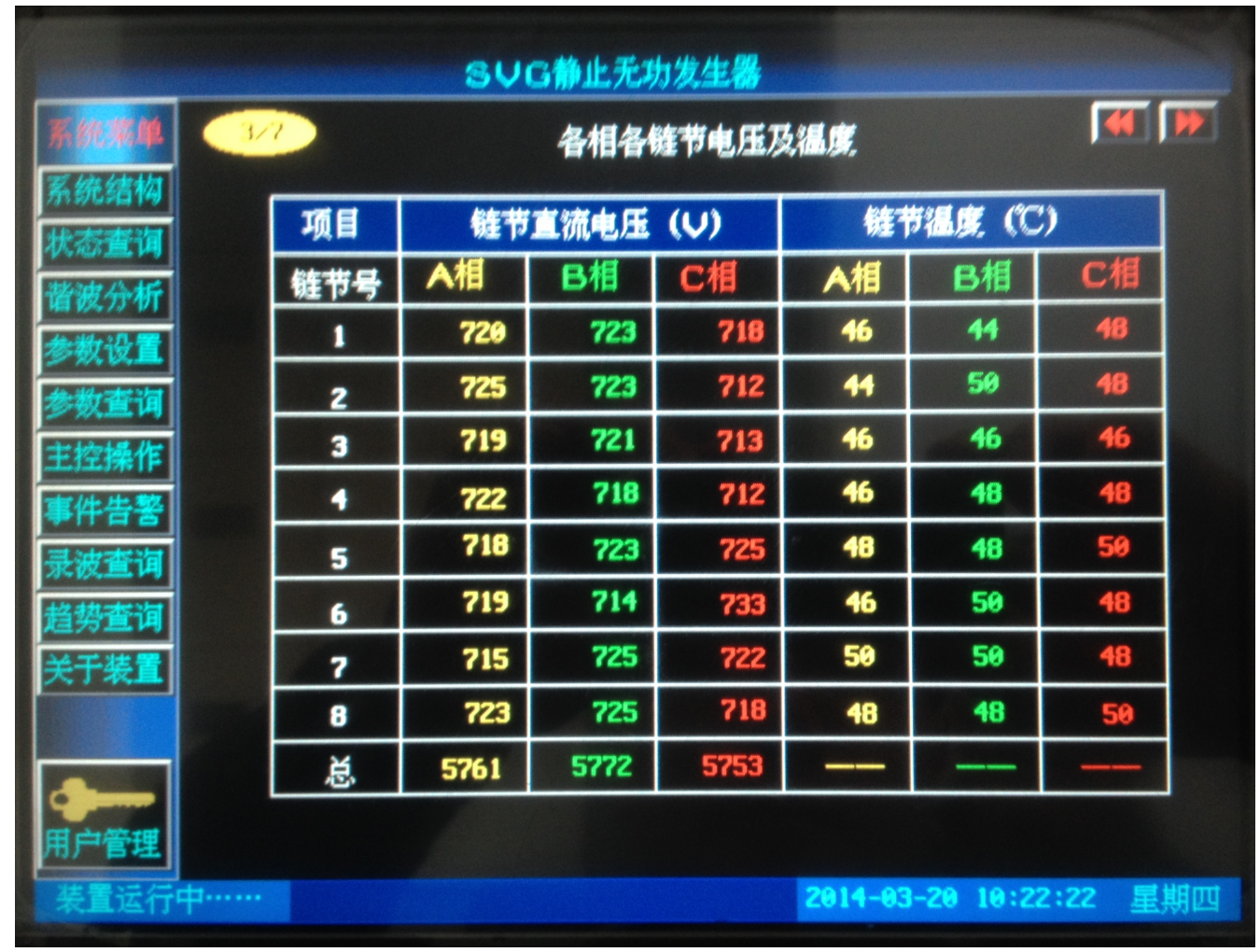

Fig. (8). DC capacitor voltages.

shift can achieve better equalizing effect, but the DC capacitor voltage waves are not quite the same. For the carrier phase shift, each phase voltage waveform of each power cell capacitance change are almost synchronous, therefore, the waveform of the capacitor voltage of each power unit is almost entirely overlap. While using the carrier cascade, for the realization of internal phase equalizing, it has to constantly adjust the modulation wave allocation orderly, thus each power unit DC capacitor discharge time in a certain period may be not the same, so that waveform obtained from each unit capacitor voltage are not the same. With this carrier cascade method, each power unit in the same phase capacitor voltage does not obtain minimum value at the same time when using carrier phase shift, or has the maximum value, therefore, when using the improved carrier cascade, phase DC side capacitor voltage fluctuation range of the average value is smaller than that of the carrier phase shift.

\section{INDUSTRY APPLICATION}

6 / 10kV STATCOM device using voltage strategy is described in this article, which has been successfully put into use. Such as dates Mining Group in Inner Mongolia Huangyu Chuan Jiang Mine and mine. STATCOM devices offers a touch screen interface, and we can see refreshed power unit DC side capacitor voltage, shown in Fig. (8). As can be seen from Fig, STATCOM at runtime each power unit DC capacitor voltage is substantially controlled in the vicinity of the reference value (reference value is $720 \mathrm{~V}$ ), and the deviation is relatively small, which shows the effectiveness of the DC capacitor balance control strategies used in this paper.

\section{CONCLUSION}

For normal operation cascaded H-bridge STATCOM, it often has DC side capacitor voltage balance control problems, this paper proposes a hierarchical control method, through the overall control, inter phase equalizing and internal phase equalizing three measures to balance the DC side of the inner phase capacitor voltage, we can solve the STATCOM DC side equalizing problems. For inter phase equalization, we use zero-sequence voltage injection method, which does not bring pollution as negative sequence voltage injection method. For STATCOM with the use of the carrier cascade method PWM, we will do real-time adjustment of the modulation wave allocation rules according to DC capacitor voltage, and achieve energy balance of Inverter Bridge, solving DC capacitor voltage phase problems. The internal phase equalizing strategy does not require additional controllers, and there is no loss of control. Simulation and industrial application prove the control strategy proposed in this paper, which is simple and easy for industry to get a good DC side equalizing effect with good prospects.

\section{CONFLICT OF INTEREST}

The authors confirm that this article content has no conflicts of interest.

\section{ACKNOWLEDGEMENTS}

This work is supported by the Research Fund for the Doctoral Program of Higher Education of China (No. 20110095110014). 


\section{REFERENCES}

[1] B. Singh, R. Saha, A. Chandra, and K.A. Haddad, "Static synchronous compensators (STATCOM): a review," Power Electronics, IET, vol. 2, no. 4, pp. 297-324, 2009.

[2] Y. Guo, X. Zhou, X. Zhang, and H. Chen "Nonlinear control of STATCOM under unbalanced condition," Electric Power Automation Equipment, vol. 32, no. 2, pp. 50-55, 2012.

[3] Y. Chen, G. Li, W. Liu, X. Zhang, and X. Zhao, "New topology for unbalance compensation of cascaded STATCOM with star configuration," Electric Power Automation Equipment, vol. 34, no. 2, pp. 108-113, 2014.

[4] D.J. Hanson, M.L. Woodhouse, C. Horwill, D.R. Monkhouse, and M.M. Osborne, "STATCOM: a new era of reactive compensation," Power Engineering Journal, vol. 16, no. 3, pp. 151-160, 2002.

[5] W. Chang, L. Shi, S. Wang, and J. Wang, "Application of space vector modulation in $6 \mathrm{kV}$ cascade STATCOM," Power System Protection and Control, vol. 40, no. 12, pp. 95-99, 2012.

[6] J. Geng, W. Liu, and Z. Yuan, "Research on the voltage unbalance of DC capacitors of cascade STATCOM-Part one: simulations and experiments," Automation of Electric Power System, vol. 27, no. 16, pp. 53-57, 2003.

[7] J. Geng, W. Liu, and Z. Yuan, "Research on the voltage unbalance of DC capacitors of cascade STATCOM-Part two: Mathematical model," Automation of Electric Power System, vol. 27, no. 17, pp. 35-39, 2003

[8] M. L. Woodhouse, M. W. Donoghue, and M. M. Osbome, "Type testing of the GTO valves for a novel STATCOM converter," In: $7^{\text {th }}$ International Conference on AC-DC Power Transmission, London, United Kingdom, pp. 84-90, 2001.
[9] W Zhao, A. Luo, K. Peng, X. Deng, "Balancing control of DC voltage of 50Mvar STATCOM based on cascade multilevel inverters," In: Proceedings of the CSEE, vol. 24, no. 2, pp. 145-150, 2004.

[10] L. Gong, Y. Kang, J. Chen, Y. Huang, and K. Dai "DC capacitor voltage distributed control system for cascaded multilevel STATCOM," Transactions of China ElectroTechnical Society, vol. 26 , no. 10, pp. 218-223, 2011.

[11] L. Maharjan, S. Inoue, and H.A. Akagi, "Transformerless energy storage system based on a cascade multilevel PWM converter with star configuration," Industry Applications, IEEE Transactions, vol. 44, no. 5, pp. 1621-1630, 2008.

[12] C. Wan, G. Yang, T. Zhang, W. Wu, and C. Lai, "DC bus voltage balancing control of three-phase cascade power regulation system with star connection," Transactions of China ElectroTechnical Society, vol. 27, no. 12, pp. 256-263, 2012.

[13] T.J. Summers, R.E. Betz, and G. Mirzaeva, "Phase leg voltage balancing of a cascaded H-bridge converter based STATCOM using zero sequence injection," In: Power Electronics and Applications, 2009. EPE'09. 13 ${ }^{\text {th }}$ European Conference, pp.1-10, 2009.

[14] Z. Liu, B. Liu, S. Duan, and Y. Kang "DC capacitor voltage balancing control for cascade multilevel STATCOM," In: Proceedings of the CSEE, vol. 29, no. 30, pp. 7-12, 2009.

[15] X. Xu, Strategy Based on Multi-Level Cascade Inverter and Control STATCOM, Huazhong University of Science and Technology, China, 2004.

[16] C.Y. Zuo, Z.J. Pei, J.J. He, R.F. Gou, J. Zhu, and W. Sun, "Research on DC link capacitor voltage control strategies of the cascaded STATCOM," High Voltage Apparatus, vol. 46, no. 1, pp. 17-21, 2010.

Received: September 16, 2014

Revised: December 23, 2014

Accepted: December 31, 2014

(C) Min et al.; Licensee Bentham Open.

This is an open access article licensed under the terms of the Creative Commons Attribution Non-Commercial License (http://creativecommons.org/licenses/by-nc/3.0/) which permits unrestricted, non-commercial use, distribution and reproduction in any medium, provided the work is properly cited. 